\title{
Knowledge Value Creation Characteristics of Virtual Teams: A Case Study in the Construction Sector
}

\author{
Chalee Vorakulpipat $^{1}$ and Yacine Rezgui ${ }^{2}$ \\ ${ }^{1}$ National Electronics and Computer Technology Center, 112 Thailand Science Park, \\ Phahonyothin Rd., Klong 1, Klong Luang, Pathumthani 12120, Thailand \\ chalee.vorakulpipatanectec.or.th \\ ${ }^{2}$ School of Engineering, Cardiff University, Queen's Buildings, The Parade, \\ Cardiff CF24 3AA, United Kingdom \\ RezguiY@cardiff.ac.uk
}

\begin{abstract}
Any knowledge environment aimed at virtual teams should promote identification, access, capture and retrieval of relevant knowledge anytime / anywhere, while nurturing the social activities that underpin the knowledge sharing and creation process. In fact, socio-cultural issues play a critical role in the successful implementation of Knowledge Management (KM), and constitute a milestone towards value creation. The findings indicate that Knowledge Management Systems (KMS) promote value creation when they embed and nurture the social conditions that bind and bond team members together. Furthermore, technology assets, human networks, social capital, intellectual capital, and change management are identified as essential ingredients that have the potential to ensure effective knowledge value creation.
\end{abstract}

Keywords: Knowledge management, value creation, virtual teams, construction sector.

\section{Introduction}

Construction is a knowledge intensive industry characterized by some unique work settings and virtual organization-like modus operandi (including fragmentation, noncollocation, and short-term partnering of teams on projects) that differentiate it from other industrial sectors $[1,2]$.

It is argued that team formation is influenced not only by the inherent characteristics of the sector, but also by an increasing sophistication and complexity of design and construction processes triggered by the need to address higher building performance and quality standards, as well as the continuous introduction of new techniques and materials. These characteristics require multi-disciplinary teams with specialized expertise that have the potential to create value out of their existing knowledge. Therefore, the support for the formation of ad-hoc virtual teams becomes essential. However, more empirical research is needed to understand the socio-technical features which influence knowledge value creation in the fragmented environment of the construction industry. This is the gap the paper is addressing. A multiple case study approach is employed involving several organizations across Europe. 
The paper, first, presents the concept of knowledge value creation, and then the research methodology employed in this study. The research results are then given, followed by the discussion. Finally, the conclusions are drawn.

\section{Knowledge Value Creation}

The gaining popularity of Knowledge Management has been reinforced by the quest for innovation and value creation [3,4]. In this context, KM is perceived as a framework for designing an organization's goals, structures, and processes so that the organization can use what it knows to learn and create value for its customers and community [5].

Innovation in construction is 'the act of introducing and using new ideas, technologies, products and/or processes aimed at solving problems, viewing things differently, improving efficiency and effectiveness, or enhancing standards of living' [6]. It is argued that construction project-based forms of enterprise are inadequately addressed in the innovation literature [7]. Project-based organization focuses on the production and/or delivery side of a firm's business [8], and is characterized by 'the coexistence of a continuing organization structure, typically based on functional departments with a temporary organizational structure based on project teams' [9]. Firms across a variety of industries are increasingly experimenting with project-based models of organization to accommodate and exploit fundamental changes in the nature and roles of markets and technologies [10, 11].

Knowledge value creation is grounded in the appropriate combination of technology assets, human networks, social capital, and intellectual capital, facilitated by change management $[12,13]$. Alavi and Leidner [14] suggest that technology (in the form of knowledge management systems) is commonly used to sustain value creation. The concept of Community of Practice (CoP) [15] was introduced as an effective social activity to promote and nurture human networks which in turn motivate people to share and create knowledge. Any process within human networks resulting in the creation of social values is defined as social capital. In this context, the social capital of an organization emerges as an essential ingredient to help employees develop trust, respect, social cohesion, and understanding of others. Because social capital emphasizes on collectivism rather than individualism, distributed community members will be more inclined to connect and use electronic networks when they are motivated to share knowledge within these virtual spaces or KMS [16]. These may help foster social capital by providing the context and history of interaction and offering a motivational element (e.g. reward) to encourage people to share knowledge with each other [16]. The intellectual capital of an organization encompasses organizational learning, innovation, skills, competencies, expertise and capabilities [17]. Liebowitz and Suen [18] suggest a strong and positive relationship between the value creation capability and intellectual capital of an organization, pointing to factors such as training, R\&D investment, employee satisfaction, and relationships development. Lastly, change management plays an increasingly important role in sustaining "leading edge" competitiveness for organizations in times of rapid change and increased competition [19-21], and the future has only two predictable features - 'change and resistance to change' and the very survival of organizations will depend upon their ability not only 
to adapt to, but also to master these challenges. Therefore, study of the change process is necessary to create the requisite organizational and societal values [22].

\section{Methodology}

The research involves a European consortium from Finland, France, Germany and UK comprising key research and industry players in the sector. The specific aim of the research is to explore the distinctive social and cultural features which influence the creation of knowledge values effectively in the organizational socio-cultural environment of the construction industry. Therefore, the following research question underpins the research: "What are the distinctive social and cultural features which influence the creation of knowledge values in the organizational socio-cultural environment of the construction industry?". The methodology employed the principles of Action Research, a qualitative research method that uniquely associates research and practice through change and reflection [23]. A multiple case study approach is adopted involving four case study organizations (illustrated in Table 1).

Table 1. Case study organizations

\begin{tabular}{llll}
\hline Case Study & Profile & Business Activity & Country \\
\hline Company A & SME & Engineering & France \\
\hline Company B & Large Organization & Design \& Construction & UK \\
\hline Company C & Large Organization & Design \& Construction & Germany \\
\hline Company D & Large Organization & Design \& Construction & Finland \\
\hline
\end{tabular}

Three main instruments were used to gather data required to address the research questions: participant observation, semi-structured interviews, and documentation. Participant observation involved the researchers being immersed in the work environment of the end-users; the interviews were conducted with 24 senior staff (holding the positions of business unit, IT and human resource managers) across the four organizations; documentation involved analyzing corporate and project documents. The aim of the interviews was to analyze the strategic positioning of each organization and its technological and organizational capabilities and competencies.

\section{Findings}

The interview results indicate an overall good awareness of the respondents in relation to the challenges faced by their organization. They have identified several main factors critical to their (organization) future growth and success. These have been categorized into four main areas listed in order of identified importance: Production (factors including costs, market knowledge and product development), Human Resources (factors such as knowledge sharing, training, and human resource management, including motivation and competence), Organization / Process (factors including teamwork, political decisions and customer relations), and Technology (factors including technology adoption: perceived limitations and future needs). 
Many interviewees highlighted the need for a shared project knowledge base in a virtual team context. There is a strong belief that this would improve communication and cohesion amongst team members, and promote shared language and mental models across teams, leading to the development of trust and culture of knowledge sharing, which concurs with recent literature [24, 25].

A majority of the respondents highlighted the limitations of their current systems in supporting collaborative working, as these do not integrate seamlessly with the engineering applications used on a daily-basis, and provide therefore limited support to the practice. They have expressed concerns about the invasive nature of ICT and the need to adapt to continuous technology introduction on projects. This corroborates the interviewees' analysis on this issue: they have indicated that ICT require constant adaptation and re-configuration for new use and deployment, while offering limited growth path and scalability. In fact, gathered data suggest that team members on projects are affected more by the newness of the technology being used than by the newness of the team structure itself. The interviewees have pointed out that these problems of technology adoption can have a negative effect on individual satisfaction with the team experience and performance, as also reported in the literature [26, 27]. Conversely, when team members are able to deal with technology related challenges, high trust develops [28].

Also, a majority of respondents reported that they tend to be tied to a physical location (mainly their office) to do their jobs. For instance, the information available in the form of written specifications and drawings produced during the design stage is required by contractors to construct the building facility. However, access to this information from the Construction site tends to be limited due to the lack of availability of software / hardware resources and network facilities. Therefore, software is usually accessed from the office, and in very few instances on site. Support and maintenance is provided through many points of service representing the different ICT technology licensees.

A large majority of respondents have indicated the need for more adapted training. While specialized software training is available, respondents have highlighted the need for continuous training and learning so as to improve their level of ICT awareness and maturity. Gathered data suggests that adapted training can foster cohesiveness, team work, commitment to team goals, individual satisfaction, and higher perceived decision quality, as also highlighted in the literature [27, 29]. However, respondents did also report that short time scales, due to simultaneous involvement in projects, creates additional pressure, and leaves little time for training.

In terms of team setting, while gathered data suggests that the process involved in setting up a teamwork solution is complex and time-consuming, the team-building exercise is overall perceived as essential in order to establish a clear team structure and shared norms, as confirmed in related literature [25, 30]. Early face-to-face meetings during the team's launch phase tend to improve the team's project definition [31], to foster socialization, trust, and respect among team members [25, 32], and to enhance the effectiveness of subsequent electronic communications [33].

Several interviewees have reported the issue of clash of cultures on projects (due to their multi-national and multi-cultural dimension), and have expressed a need for the goals of the project to be shared and embraced collectively. In fact, differences in organizational affiliations can reduce shared understanding of context and can inhibit 
a team's ability to develop a shared sense of identity [34]. An important number of respondents expressed concerns about the bureaucratic and hierarchical culture in their organization, which is in several instances reproduced in teams. Issues related to motivation, trust and team cohesion have been raised. High motivation levels and job satisfaction are critical success factors in any organizational environment and even more important in a virtual environment. It was suggested that 'participatory' type of culture, with a flat structure, open communication channels, and participation and involvement in decision-making, enhances sharing of information and facilitates team cohesion, which in turn promotes trust. These are indeed important problems faced by virtual teams [35-38]. This, as reported in [26], contributes to improve employees' overall satisfaction and job effectiveness. Indeed people work together because they trust one another and successful virtual teams pay special attention to building trust throughout their lifecycle [37]. Interviewees pointed out that people generally tend to trust people rather than companies and that trust ultimately emerges where communicated information is reliable, people stand by their promises, and outcomes equal or exceed expectations. Teams with trust converge more easily [30], organize their work more quickly, and manage themselves better [37].

The interviewees reported that value creation is best reflected in their sustainability and health and safety initiatives. Sustainability goals can only be achieved if existing and new resources of knowledge and expertise inform construction activities. Some of this comes in the form of good practice and standards, but much comes from situated and contextual appreciations of sustainability goals and local practices developed within and across projects and organizational boundaries. In this respect, the participants felt strongly that knowledge sharing initiatives provide means to capture, represent, and disseminate sustainability information and experiences acquired on projects, and enable these to be nurtured within and across organizations and applied successfully in projects with real impacts. In response to the critical situation of health and safety on construction projects and the consequences in terms of image and reputation to the sector, the respondents reported the use of basic knowledge management solutions to record the number of recent incidents and then making these widely available and accessible through the company Intranet to all employees, including designers. The participants felt strongly that the capture, representation, and dissemination of health and safety measures create real values in terms of reduction of accidents on sites and improvement of the overall well being of staff and future users.

\section{Discussion}

It has been argued earlier (section 2) that technology assets, human networks, social capital, intellectual capital, and change management are important factors that underpin value creation activities [12, 13, 39]. This section answers the research question formulated earlier in the paper by articulating the findings around the above factors.

\subsection{Human Networks}

Interviewees have expressed concerns about the potential lack of face-to-face interactions during the virtual team lifecycle and in particular during the inception stage where the vision, mission, and goals can be communicated and shared. They have 
suggested the need to develop strong communication and collaboration protocols, including code of conduct, standards for availability and acknowledgement.

Team collaboration through face-to-face communication creates stronger social relationships while these are difficult to establish in virtual contexts due to the lack of emotional expressions. Therefore, team members in a virtual team are aware of the greater societal acceptance of face-to-face rather than virtual interaction. Virtual communication such as email may form bridges between people (e.g. across different geographical locations) but it does not bond team members enough together. Construction relies heavily on ad-hoc relationships between individuals and companies. This seems to influence the success of a project.

That is, collectivist or participatory culture is needed in a team to help create network ties. Therefore, the organization's knowledge values must be created through the network of relationships possessed by people in collectivist cultures. Strong social relationships and collectiveness are perceived as a critical factor to create more opportunities for team members to participate in problem-solving and decision making, and offer a range of different skills, abilities, knowledge, and experience to ensure that creative ideas are supported.

\subsection{Social Capital}

Much of valuable knowledge is tacit and nurtured in small social networks. It was suggested that a "participatory" type culture, with a flat structure, open communication channels, and participation and involvement in decision-making, enhances sharing of information and facilitates team cohesion, which in turn promotes respect and trust. This contributes to improving employees' overall satisfaction and job effectiveness.

A culture that recognizes tacit knowledge and social networks results in the promotion of open dialogue between staff allowing them to develop social links and share understandings, as outlined in Rezgui [12]. The need to share tacit knowledge by face-to-face social communication has emerged from the research, to foster social capital. This method is perceived to (a) break down barriers between employees and management, (b) establish stronger relationships among them, (c) allow employees to reduce personal barriers and gain confidence, and (d) practice and improve their knowledge sharing skills.

Social networks can be facilitated and nurtured by providing informal forums that can be assimilated into communities of practice. These are complemented with virtual spaces to share knowledge (including sensitive information) protected by a role access control system. The interviewees confirmed that employees need the creation of strong relationships and networks ties across projects and organizations and avoid any conflicts so that to maintain a good level of relationship between project members. In fact, it has been shown that human networks can only be effective if the social conditions that underpin collaboration are met (including trust). This is where conscientious behavior reveals important. This emphasizes the role that social capital plays in creating organizational value underpinned by strong human networks. A participatory culture helps develop trust, respect, and understanding for others at different levels in the construction sector. Clearly, a culture of confidence and trust in which people are willing to communicate is perceived to initiate KM. 


\subsection{Technology}

The results suggest that controlled access to information and knowledge enhances trust in technology, an important factor in promoting a culture of knowledge sharing facilitated by ICT. Moreover, the results show that there is a lack of a clear vision and ICT strategy. The prevailing policy based on acquiring off-the-shelf solutions fails to deliver. These commercial solutions tend neither to accommodate existing practices nor build on existing corporate solutions.

The results show the concerns about lack of social-oriented communication and social events due to the tendency to completely rely on computer technology, which results in people feeling that they are usually "stuck" in front of their computers. This perception leads to KM fallacies or traps that directly influence the perceived functionality of IT applications for the support of KM initiatives [40]. As also reported in Huysman and Wulf [16], these fallacies relate to the tendency of organizations to concentrate too much on the IT role supporting KM practices, especially knowledge sharing, resulting in the "IT trap". It is important to recognize that IT is not independent from the social environment, as it is not the technology itself, but the way people use it that determines the role of IT in supporting knowledge management practices [16]. Therefore, the organization's success with the use of IT will not depend on IT skills, but the appropriate social context that can benefit from electronic communication technology [41]. This requires the use of socially embedded technologies or collaborative system such as KMS or groupware, influenced by the belief structures (perceived ease-of-use and perceived usefulness) of TAM [42]. It is suggested that collaboration through groupware is highly valued overall, and the functionality like discussion forum has been described as important in nurturing knowledge sharing within a social context, as confirmed in related literature [43, 44].

\subsection{Intellectual Capital}

Issues pertinent to organizational learning, innovation, skills, and best practices were raised. These also include improved competence management and sustained motivation through adapted training and incentive / reward systems. Whilst the organization has an overall good awareness of KM practices, there are some limitations that may have caused only a gradual improvement in KM over several years. These limitations revealed the following issues:

- Employees have expressed strong concerns about sharing their knowledge, arguing about confidentiality implications and Intellectual Property Rights (IPR) issues as they fear that their knowledge will be stolen or given away to others.

- Dominant bureaucratic (hierarchical) organizational structure in place is perceived to inhibit the development of skills and best practices amongst employees and managers who are of higher social rank, also leading to personal barriers.

The coding and sharing of best practice is one of the common initiatives employed to initiate organizational KM [14], and knowledge sharing can take place only once a corporate knowledge repository is made widely accessible to staff [45]. These have helped improve knowledge connectivity, access, and transfer across the construction sites. 
An appropriate representation of the history of knowledge sharing activities may be useful since it allows human actors to better understand and refer to past interactions [16]. As reported in the results, the respondents promoted their idea about recording a number of recent incidents and making them available through the organization Intranet. Not only this, it is suggested that this explicit knowledge sharing method should be combined with the tacit knowledge sharing method. This concept is in line with the concept of how to augment collocated communication spaces with complex materials [46]. They present the Envisionment and Discovery Collaboratory (EDC), an environment in which participants collaboratively discuss issues of mutual interest. The EDC supports face-to-face discussion activities by bringing together individuals who share a common problem. Moreover, the EDC provides an additional systematic feature to store historic data. Computer recognition of physical representations is designed to allow the computer to reduce the effort of capturing and formalizing problem information. They perceive that face-to-face discussions without some capture mechanism may be rich interactions, but only participants around the table benefit, and when the discussion is over the interaction is lost.

\subsection{Change Management}

Change management may include technical and human issues. In terms of technical sides, interviewees expressed concerns about the invasive nature of ICT and the need to adapt to continuous technology introduction across projects in which they are involved, suggesting that project team members are affected more by the newness of the technology being used than of the team structure itself (which changes from one project to another). They pointed out that these problems of technology adoption can have a negative effect on individual satisfaction with the team experience and performance. Conversely, when team members are able to deal with technology related challenges, a culture of knowledge sharing is promoted. There is a poor software adoption culture as ICT solutions, including previously deployed KMS, tend to lack flexibility and scalability as the needs of the organization and users evolve.

In terms of human issues, the participants have acknowledged that knowledge value creation would imply new approaches to the management of human resources, information and knowledge within their organization. While the potential gains have been well articulated, concerns have been raised in that the necessary changes might be resisted. Therefore, to be effective, any KM program should be incorporated within a change management program that promotes a "participatory" type of culture while taking into account the team-based structure and discipline-oriented nature of the Construction industry.

Clearly, the research acknowledges the pivotal and strategic role that human networks, social capital, technology, and intellectual capital play in enhancing value creation in the construction sector. This has resulted in increased awareness, knowledge quality, and business intelligence, which have in turn triggered a value added dimension that did not exist prior to initiating the change processes.

\section{Conclusion}

It is vital that the construction sector migrates to a knowledge value creation culture where technology assets, human networks, social capital, intellectual capital, and 
change management must be blended successfully to ensure effective knowledge value creation. Understanding the social and cultural features, which influence knowledge value creation in the fragmented socio-cultural environment of the construction industry, is needed. As far as the research question is concerned, crucial cultural features emerging from the results include collectiveness and conscientiousness. Collectiveness represents collectivist culture and social relationship and Conscientiousness represents avoidance of uncertainty and risk and being patient with uncertain situations.

Firstly, the study shows that the organizations clearly support employees' opportunity to work in a team rather than to work individually. Collectivist or participatory culture is needed in a team to help create network ties. Therefore, the organization's knowledge values must be created through the network of relationships possessed by people in collectivist cultures. The cases confirm that strong social relationships and collectiveness are perceived as a critical factor to create more opportunities for team members to participate in problem-solving and decision making, and offer a range of different skills, abilities, knowledge, and experience to ensure that creative ideas are supported. a knowledge-based organization needs all of its employees to share a culture that promotes the virtues of knowledge acquisition and sharing, requiring a number of essential attributes, as pointed out by Rezgui [12]. The collective characteristic of a virtual team is exemplified by the dimension given to team working. However, it has been shown that human networks can only be effective if the social conditions that underpin collaboration are met (including trust). This emphasizes the role that social capital plays in creating organizational value underpinned by strong human networks. A participatory culture helps develop trust, respect, and understanding for others at different levels in the construction sector. Clearly, a culture of confidence and trust in which people are willing to communicate is perceived to initiate knowledge value creation.

Conscientiousness may encourage opportunities for creating relationships and network ties among teams. However, the research so far does not claim that social capital with conscientiousness is effective. It may create only the "opportunity" to bridge people (such as those who are from different geographical locations) together, but does not bond them together. Moreover, conscientiousness may help channel people in the organization to the same goals and mission. Nevertheless, it does not confirm that this is an organizational advantage as conscientious employees have never raised concerns, requests or comments explicitly, so that the management does not know the employees' needs.

To sum up, the research has explored and identified distinctive socio-cultural features influencing knowledge value creation of virtual teams in the construction industry. More research is needed to validate the above results and deepen the understanding of the socio-organizational factors affecting value creation in industry.

\section{References}

1. Rezgui, Y.: Review of Information and the State of the Art of Knowledge Management Practices in the Construction Industry. The Knowledge Engineering Review 16, 241-254 (2001) 
2. Rezgui, Y.: Exploring Virtual Team-Working Effectiveness in the Construction Sector. Interacting with Computers 19, 96-112 (2007)

3. Aranda, D.A., Molina-Fernandez, L.M.: Determinants of Innovation through a Knowledge-based Theory Lens. Industrial Management \& Data Systems 102, 289-296 (2002)

4. Huseby, M., Chou, S.T.: Applying a Knowledge-focused Management Philosophy to Immature Economies. Industrial Management \& Data Systems 102, 17-25 (2003)

5. Choo, C.W.: Closing the Cognitive Gaps: How People Process Information. In: Marchand, D., Davenport, T., Dickson, T. (eds.) Mastering Information Management, pp. 245-253. FT-Prentice Hall, Harlow (2000)

6. CERF: Guidelines for Moving Innovations into Practice. In: CERF, Working Draft Guidelines for the CERF International Symposium and Innovative Technology Trade Show Washington, DC (2000)

7. Barrett, P., Sexton, M.: Innovation in Small, Project-Based Construction Firms. British Journal of Management 17, 331-346 (2006)

8. Artto, K.A.: Global Project Business and Dynamics of Change. Helsinki: TEKES/PMA (1998)

9. Grant, R.M.: Contemporary Strategic Analysis: Concepts, Techniques, Applications. Blackwell Publishers, Oxford (1997)

10. DeFillippi, R.J., Arthur, M.B.: Paradox in Project-Based Enterprise: The Case of Film Making. California Management Review 40, 1-15 (1998)

11. Kanter, R.M.: The Frontiers of Management. Harvard Business School Press (1997)

12. Rezgui, Y.: Knowledge Systems and Value Creation: An Action Research Investigation. Industrial Management \& Data Systems 107, 166-182 (2007)

13. Vorakulpipat, C., Rezgui, Y.: Value Creation: The Future of Knowledge Management. Knowledge Engineering Review 23, 283-294 (2008)

14. Alavi, M., Leidner, D.: Review: Knowledge Management and Knowledge Management Systems: Conceptual Foundations and Research Issues. MIS Quarterly 25, 107-136 (2001)

15. Wenger, E., McDermott, R., Snyder, W.M.: Cultivating Communities of Practice: A Guide to Managing Knowledge. Harvard Business School Press, Cambridge (2002)

16. Huysman, M., Wulf, V.: IT to Support Knowledge Sharing in Communities, towards a Social Capital Analysis. Journal of Information Technology 21, 40-51 (2006)

17. Rastogi, P.N.: Knowledge Management and Intellectual Capital - The New Virtuous Reality of Competitiveness. Human Systems Management 19, 39-48 (2000)

18. Liebowitz, J., Suen, C.Y.: Developing Knowledge Management Metrics for Measuring Intellectual Capital. Journal of Intellectual Capital 1, 54-67 (2000)

19. McAdam, R., Galloway, A.: Enterprise Resource Planning and Organisational Innovation: A Management Perspective. Industrial Management \& Data Systems 105, 280-290 (2005)

20. Wheatcroft, J.: Organizational change, the story so far. Industrial Management \& Data Systems 100, 5-9 (2000)

21. Reddy, S.B., Reddy, R.: Competitive agility and the challenge of legacy information systems. Industrial Management \& Data Systems 102, 5-16 (2002)

22. Christiansson, P.: Next Generation Knowledge Management Systems for the Construction Industry. In: CIB W78 Construction IT Bridging the Distance, Auckland (2003)

23. Avison, D., Lau, F., Myers, M., Nielsen, P.A.: Action research. Communications of the ACM 42, 94-97 (1999)

24. Crampton, C.: The Mutual Knowledge Problem and its Consequences for Dispersed Collaboration. Organization Science 12, 346-371 (2001)

25. Suchan, J., Hayzak, G.: The Communication Characteristics of Virtual Teams: A Case Study. IEEE Transactions on Professional Communications 44, 174-186 (2001) 
26. Kayworth, T., Leidner, D.: The Global Virtual Manager: A Prescription for Success. European Management Journal 18, 183-194 (2000)

27. Van Ryssen, S., Hayes Godar, S.: Going International Without Going International: Multinational Virtual Teams. Journal of International Management 6, 49-60 (2000)

28. Jarvenpaa, S., Leidner, D.: Communication and Trust in Global Virtual Teams. Organization Science 10, 791-815 (1999)

29. Warkentin, M., Beranek, P.M.: Training to Improve Virtual Team Communication. Information Systems Journal 9, 271-289 (1999)

30. Sarker, S., Lau, F., Sahay, S.: Using an adapted grounded theory approach for inductive theory building about virtual team development. Database for Advances in Information Systems 32, 38-56 (2001)

31. Ramesh, V., Dennis, A.R.: The Object-Oriented Team: Lessons for Virtual Teams from Global Software Development. In: HICSS35, Hawaii (2002)

32. Maznevski, M., Chudoba, K.: Bridging Space Over Time: Global Virtual Team Dynamics and Effectiveness. Organization Science 11, 473-492 (2001)

33. Powell, T.C., Dent-Micallef, A.: Information Technology as Competitive Advantage: The Role of Human, Business, and Technology Resources. Strategic Management Journal 18, 375-405 (1999)

34. Espinosa, J.A., Cummings, J.N., Wilson, J.M., Pearce, B.M.: Team boundary issues across multiple global firms. Journal of Management Information Systems 19, 157-190 (2003)

35. Kezsbom, D.: Creating teamwork in virtual teams. Cost Engineering 42, 33-36 (2000)

36. Alexander, S.: Virtual teams going global. InfoWorld 46, 55-56 (2000)

37. Lipnack, J., Stamps, J.: Virtual Teams: People Working Across Boundaries with Technology, 2nd edn. Wiley, New York (2000)

38. Solomon, C.: Managing virtual teams. Workforce 80, 60-65 (2001)

39. Vorakulpipat, C., Rezgui, Y.: An Evolutionary and Interpretive Perspective to Knowledge Management. Journal of Knowledge Management 12, 17-34 (2008)

40. Huysman, M., de Wit, D.: Knowledge Sharing in Practice. Kluwer Academics, Dordrecht (2002)

41. Zack, M.H., McKenny, J.L.: Social Context and Interaction in Ongoing ComputerSupported Management Groups. In: Smith, D.E. (ed.) Knowledge, Groupware and the Internet. Butterworth-Heinemann, Boston (2000)

42. Davis, F.D.: Perceived Usefulness, Perceived Ease of Use, and User Acceptance of Information Technology. MIS Quarterly 13, 319-340 (1989)

43. Ellis, C.A., Gibbs, S.J., Rein, G.L.: Groupware: Some Issues and Experiences. Communications of the ACM 34, 38-58 (1991)

44. Poltrock, S., Grudin, J.: Groupware and Workflow: A Survey of Systems and Behavioral Issues. In: CHI 1995, ACM Conference on Human Factors in Computing Systems, Denver (1995)

45. Davenport, T., Prusak, L.: Working Knowledge: How Organizations Manage What They Know. Harvard Business School Press, Boston (1998)

46. Fischer, G., Scharff, E., Ye, Y.: Fostering Social Creativity by Increasing Social Capital. In: Huysman, M., Wulf, V. (eds.) Social Capital and Information Technology. MIT-Press, Cambridge (2004) 